\title{
The mechanism of farmland marginalization in Chinese mountainous areas: Evidence from cost and return changes
}

\author{
LI Shengfa ${ }^{1,2,3},{ }^{*}$ LI Xiubin ${ }^{2,3}$ \\ 1. Guangdong Open Laboratory of Geospatial Information Technology and Application, Guangzhou Institute of \\ Geography, Guangzhou 510070, China; \\ 2. Key Laboratory of Land Surface Pattern and Simulation, Institute of Geographic Sciences and Natural Re- \\ sources Research, CAS, Beijing 100101, China; \\ 3. University of Chinese Academy of Sciences, Beijing 100049, China
}

\begin{abstract}
Farmland marginalization has become the main trend of land-use change in the mountainous areas of China. Using annual survey data of major agricultural production costs and earnings at national and provincial levels in China, this study aims to analyze the reasons and mechanism behind farmland marginalization in mountainous areas. We find that farmers on plains are able to reduce their per mu labor input effectively through intensive use of agricultural machinery, which has minimized the impact of the increase in labor price. However, it is extremely challenging for farmers in mountainous areas to use the same method owing to the rough terrain. Thus, per laborer farming area in these areas has increased relatively slowly, causing a widening gap in agricultural labor productivity between the two regions. With the rapid rise in labor costs since 2003, the marginalization of cultivated land in mountainous areas is evident. In 2013, the net profit of agricultural production in mountainous China fell below zero. Since 2000, the land-use and land-cover change in these areas was characterized by the reduction of farmland area, reforestation, and the enhancement of the NDVI value. The high correlation between the NDVI change rate and the ratio of change in farmland $(r=$ $-0.70)$ and forest $(r=0.91)$ in mountainous areas at provincial level further attests to the trend of farmland marginalization there. Finally, we summarize the mechanism of such marginalization against the backdrop of the rapid increase in the opportunity cost of farming and the rapid fall of agricultural labor forces in mountainous areas. This study contributes to a deep understanding of the development process of farmland marginalization and abandonment as well as forest transition in Chinese mountainous areas.
\end{abstract}

Keywords: farmland marginalization; farmland abandonment; labor costs; returns; agricultural labor productivity; mountainous areas; China

Received: 2018-04-19 Accepted: 2018-06-10

Foundation: GDAS' Project of Science and Technology Development, No.2018GDASCX-0903, No.2017GDASCX-0101, No.2018GDASCX-0101; National Basic Research Program of China (973 Program), No.2015CB452706;

National Natural Science Foundation of China, No.41801101, No.41161140352

Author: Li Shengfa, PhD and Assistant Professor, specialized in land use change analysis. E-mail: li_shengfa@126.com

"Corresponding author: Li Xiubin, Professor, E-mail: lixb@igsnrr.ac.cn 


\section{Introduction}

The marginalization of land refers to the continuous reduction of the economic productivity of certain types of land use under the combined impacts of various factors, such as social, economic, and environmental changes (Liu et al., 2005). When the land net profit is reduced to zero or less, current land-use type shifts to a more extensive type. If there is no alternative to economical productivity, the land will be abandoned. Farmland abandonment is the most obvious manifestation of farmland marginalization. Since the second half of the 20th century, noteworthy farmland abandonment and the subsequent restoration of abandoned farmlands (forest transition) have been occurring in many hilly and mountainous regions around the world, especially in mountainous areas of Europe (Meyfroidt et al., 2011). According to existing knowledge, current global farmland marginalization and abandonment are the result of the exodus of agricultural labor forces, under the processes of industrialization and urbanization (Rudel et al., 2005; Lambin et al., 2010; Li et al., 2017a). Since China reached the Lewis turning point in 2003 (Zhang et al., 2011a), the trend of farmland marginalization in parts of China is likely to be obvious, and the number of reports about farmland abandonment has continued to increase (Li et al., 2017a). The China Household Finance Survey, conducted by the Southwestern University of Finance and Economics, reported that 13.5\% of agricultural land nationwide in 2011 and 15\% in 2013 were idle (Gan et al., 2015). Case studies show that farmland abandonment mostly occurred in mountainous areas (Li et al., 2017a), such as Chongqing Municipality (Zhang et al., 2011b; Li et al., 2013; Shi et al., 2016), provinces of Sichuan (Xu et al., 2010), Fujian (Luo, 2008; Yi, 2014), western Hunan (Huang et al., 2009; Luo et al., 2015), Guizhou (Zhao et al., 2016), southern Ningxia (Tian et al., 2010), southeastern Gansu (Chang, 2014), and southern Jilin (Zhao, 2012).

Existing studies have revealed the reasons and influencing factors of farmland abandonment at parcel level (Gellrich et al., 2007; Zhang et al., 2014a; Shi et al., 2016) and household level (Li et al., 2014; Yan et al., 2016). At parcel level, zero rent is the root cause of farmland abandonment (Zhang et al., 2014b); at household level, the rise of farming opportunity costs leads to farmers' decision to abandon farming (Li et al., 2011; Yan et al., 2016); while the underlying drivers are industrialization and urbanization (MacDonald et al., 2000; Kozak, 2003; Li et al., 2011). However, there is no comprehensive summary of the mechanism of farmland marginalization. In particular, there is no quantitative analysis of the reasons why farmland marginalization mainly occurs in mountainous areas. Therefore, using the data from China Agricultural Production Costs and Returns Compilation, this study analyzes the changes of labor costs in China's agricultural production since the mid-1990s, as well as the response of farmers to labor costs. By comparing the different responses of farmers in mountainous and plain areas to the rising labor costs, and the different results of costs and returns in agricultural production, this study first analyzes the economic characteristics of farmland marginalization in mountainous areas. Next, using land-use data and remote-sensing data, this study analyzes the changes of farmland and forest area and the spatio-temporal variation characteristics of the vegetation index in mountainous areas of China from 1990 to 2010. The analysis results are able to present realistic evidence of farmland marginalization in China. Finally, we summarize the whole process and mechanism of farmland marginalization in China's mountainous areas. 


\section{Materials and methods}

\subsection{Materials}

The national and provincial data of agricultural production costs, benefits, and labor use used in this study are from China Agricultural Production Costs and Returns Compilation. The compilation is published annually by the Department of Price, which is under the supervision of China's National Development and Reform Commission. The data for total power of agricultural machinery of Chongqing Municipality and Heilongjiang Province are derived from Chongqing Statistical Yearbook and Heilongjiang Statistical Yearbook, respectively. Land-use data come from the China Eco100-Spatiotemporal Distribution Dataset of Ecosystem Types in China (1990-2010), which were produced by the Institute of Geographic Sciences and Natural Resources Research, Chinese Academy of Sciences. These data include seven types of ecosystems, which are farmland, forest, grassland, wetland, desert, settlement, and others, with a resolution of $100 \mathrm{~m}$. The comprehensive evaluation accuracy of the data is $94.3 \%$ (Xu et al., 2017). The NDVI data come from the China MODIS-NDVI monthly synthetic product downloaded from Geospatial Data Cloud (http://www.gscloud.cn/) with a spatial resolution of $250 \mathrm{~m}$.

\subsection{Research framework}

Farmland marginalization is defined a process of declining land rent under current land-use type. The increase of cost, the decrease of income, or the combination of both will cause rent to decrease. In order to promote farmers' enthusiasm for grain production, stabilize national grain production, and increase farmers' incomes, the Chinese government has continuously introduced beneficial farming policy, like tax exemptions or reductions, direct subsidies, and raising of state procurement prices for grains since 2004, thereby implying that the main reason for the decline in farmland rent is the increase in costs. During the processes of industrialization and urbanization, the rapid increase in farming costs was mainly caused by the rise of agricultural labor cost. Specifically, after the Lewis turning point, the rise in the non-agricultural wage leads first to a rise in farming opportunity cost and then to a rise in the agricultural labor price. Agricultural labor costs are related to labor price and labor use per $\mathrm{mu}\left(1 \mathrm{mu}=666.7 \mathrm{~m}^{2}\right)$. Under the premise of no change in labor use per $\mathrm{mu}$, a substantial increase in the labor price inevitably leads to a rapid increase in labor costs. Meanwhile, when the farming opportunity cost increases, farmers reallocate family laborers with the goal of the household utility maximization, based on the quantity and quality of the household labor force and farmland. Hence, an increasing number of farmers would enter off-farm industries. Therefore, under the joint influence of a rural labor exodus and rising labor prices, farmers would adjust their farming practices to maximize their labor productivity rather than land productivity (Chen et al., 2009; Xu et al., 2015), in order to reduce labor use per mu, with the final aim of reducing labor costs (Tian et al., 2009; Xin et al., 2011). These adjustments include farming structure and cropping system adjustment, farmland area adjustment, and adopting factor substitution (Xin et al., 2011; Yan et al., 2016).

For the adjustment of farming structure and cropping systems, a rapid rise of agricultural labor costs would impel farmers to expand plantings of crops with higher labor productivity, and reduce those with lower labor productivity. For example, farmers in southern China re- 
cently have tended to increase the vegetable planting area and reduce the rice planting area, and have changed double cropping of rice to single cropping; while farmers in northern China have tended to reduce the cultivated area of wheat and expand the area of maize (Wang et al., 2015).

For the adjustment of farmland area, a rapid rise of agricultural labor costs would encourage some famers to rent out their farmland, while other farmers with higher labor productivity would rent more farmland to enlarge farming scale (Xin et al., 2011), thereby realizing large-scale production and enhancing overall agricultural labor productivity.

Factor substitution is farmers' direct response to the relative price changes among the factors. According to the theory of induced technical innovation, when the price of agricultural labor rises and makes labor cost become the most important restraint factor in agricultural production, it induces farmers to adopt labor-saving agricultural technologies (Zhu et al., 2007; Xin et al., 2011), that is, to increase labor-saving input in order to reduce labor input (Chen et al., 2009).

Because there are significant differences in natural conditions, adjusted farming practices vary between farmers in mountainous and plain areas. Such differences would result into different changes per mu labor days, agricultural labor productivity, labor costs, and net profit (rent), and subsequently to different changes in land-use types, which are eventually revealed in land use and cover map. Farmland marginalization would lead to land abandonment and land-use type changes in favor of revegetation and reforestation in hilly and mountainous areas. Under these assumptions, total farmland area should decrease in mountainous areas while forest areas should expand (Figure 1).

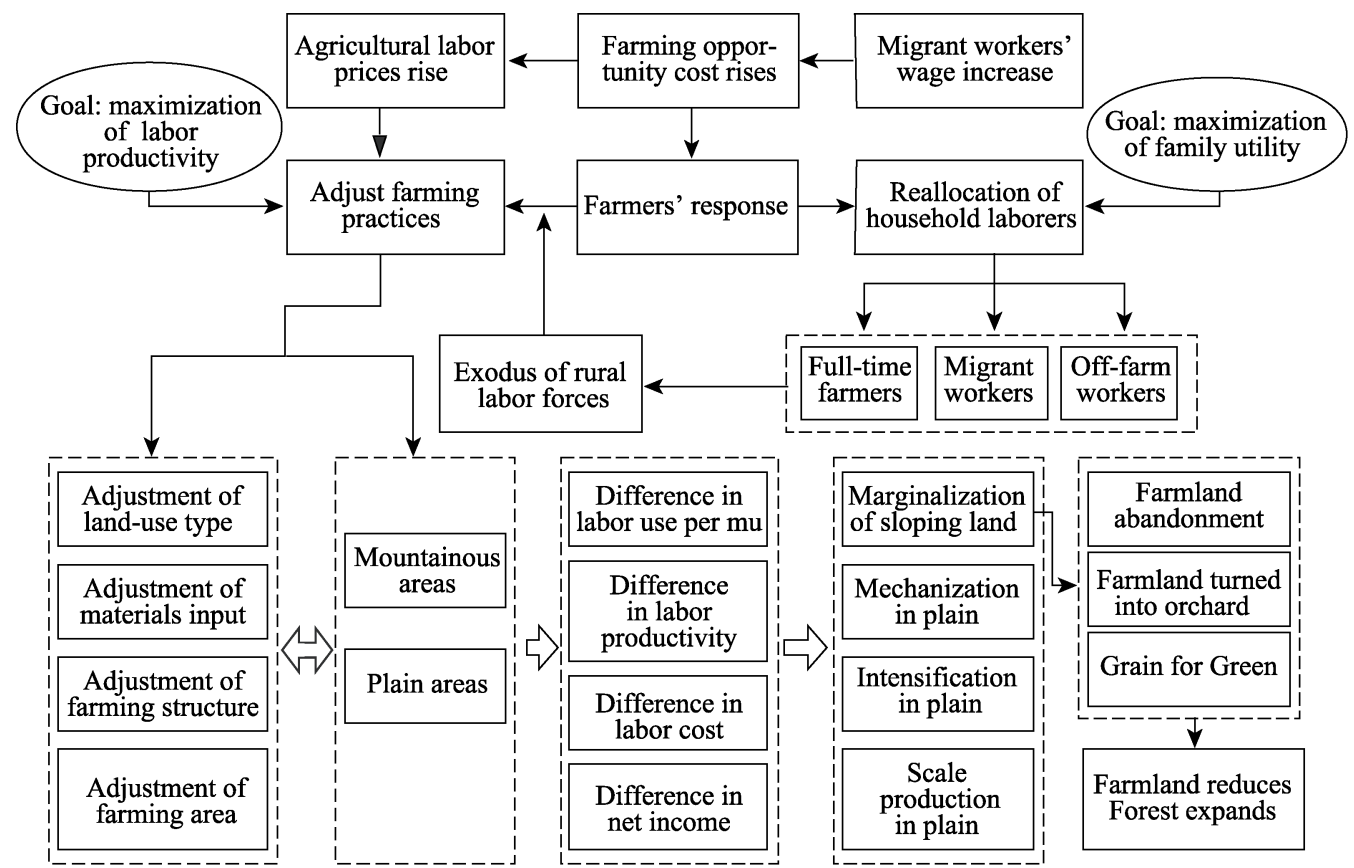

Figure 1 Research framework of farmland marginalization

\subsection{Methods}

There are many ways to measure agricultural labor productivity, such as per laborer yield or 
net output value, per laborer farming area, and labor use per unit of agricultural products. In order to compare agricultural labor productivity in different regions and different periods, this study uses the grain yield per unit of working days. The equation for this calibration is as follows:

$$
E=P / L
$$

where $E$ is agricultural labor productivity, $P$ is grain yield per mu, and $L$ is labor use per mu.

Compared with the change of land-use types, the NDVI is more timely in reflecting the information about land-cover change. After farmlands are abandoned, the time for vegetation restoration varies greatly among regions. Even in the southern mountainous areas with abundant rainfall, the restoration of vegetation after farmland abandonment is a gradual process. In a few years after abandonment, the abandoned land might not change significantly in land-use type, but its status of utilization can be reflected by the NDVI. Therefore, in addition to the analysis of changes in land-use types in mountainous areas, this study also uses the NDVI data to analyze the vegetation changes and the correlation between the NDVI change and the change of farmland and forest area. The major difference between the annual NDVI curves of abandoned farmland and managed farmland is the duration of high values; the former is longer than the latter (Alcantara et al., 2012). Thus, the annual average value of the NDVI can more effectively reflect the development of farmland marginalization in mountainous areas than the maximum value can. Consider the need for time to restore vegetation, we choose the annual average rate of NDVI changes from 2000 to 2013 to reveal the overall trend of vegetation in mountainous areas.

Owing to the ambiguities and uncertainties of the definition of mountainous areas (Jiang et al., 2009), it is very difficult to define a mountain range accurately. In addition, the main focus of this study is the difference in rural response between households in rugged terrain and those in flat areas. Therefore, this study does not strictly define mountainous areas and plains. Instead, when analyzing the changes of costs and benefits, owing to the data limitation, we select provinces (includes municipalities) with the most obvious topographic features as proxies for mountainous and plain areas. Based on the topographical features of each province and their proportion of sloping farmland, seven provinces and municipalities with the highest proportions of mountainous and hilly area and the highest proportions of cultivated land (above 6 degrees) were chosen to represent mountainous areas, namely, Chongqing, Guizhou, Yunnan, Sichuan, Gansu, Shanxi, and Shaanxi. Excluding Shanxi and Gansu, the other five provinces have more than $60 \%$ of sloping farmland, of which the highest proportion is Chongqing Municipality, the typical representation of mountainous areas, with about $85 \%$ of sloping farmland. Seven provinces with the highest percentages of plain area and the highest proportion of flat farmland (less than 6 degrees) are selected to represent plains, namely, Heilongjiang, Jilin, Hebei, Shandong, Henan, Jiangsu, and Anhui. Excluding Jilin, the proportion of flat farmland in other provinces is more than $90 \%$, of which the per laborer farmland area in Heilongjiang is as high as $30.5 \mathrm{mu}$. Hence, Heilongjiang is a typical representative of China's agricultural mechanization and large-scale production in plain areas. When analyzing the changes of land use and cover, in order to understand the changing characteristics of mountainous areas better, this study uses mountain counties (MCs) defined by the China County Statistical Yearbook as the analysis area in contrast to hilly counties (HCs) and plain counties (PCs). According to the definition of the China County Statistical Yearbook, mountain counties refer to those with mountainous areas 
of more than $80 \%$, of which there are about 900 counties, accounting for about $45 \%$ of the total land area.

\section{Results}

\subsection{Changes in agricultural labor costs and farmers' response}

\subsubsection{Agricultural cost change}

Since 2003, the wage of migrant workers in China has risen rapidly by about $10 \%$ every year (Xin et al., 2011; Lu, 2012), leading to an increase in farming opportunity cost, which in turn has led to a rapid increase of labor costs in agricultural production. During 2003-2013, employed wages of agricultural laborers increased by 5.1 times, while the costs of agricultural materials and services (excluding machinery service fee) only doubled. Therefore, in per mu agricultural production costs, labor costs are rising at a higher rate than the costs of agricultural materials and services. By 2011, the labor costs of the three main grain crops in China reached 283 yuan/mu and exceeded the costs of agricultural materials and services for the first time, becoming the main cost in agricultural production (Figure 2).

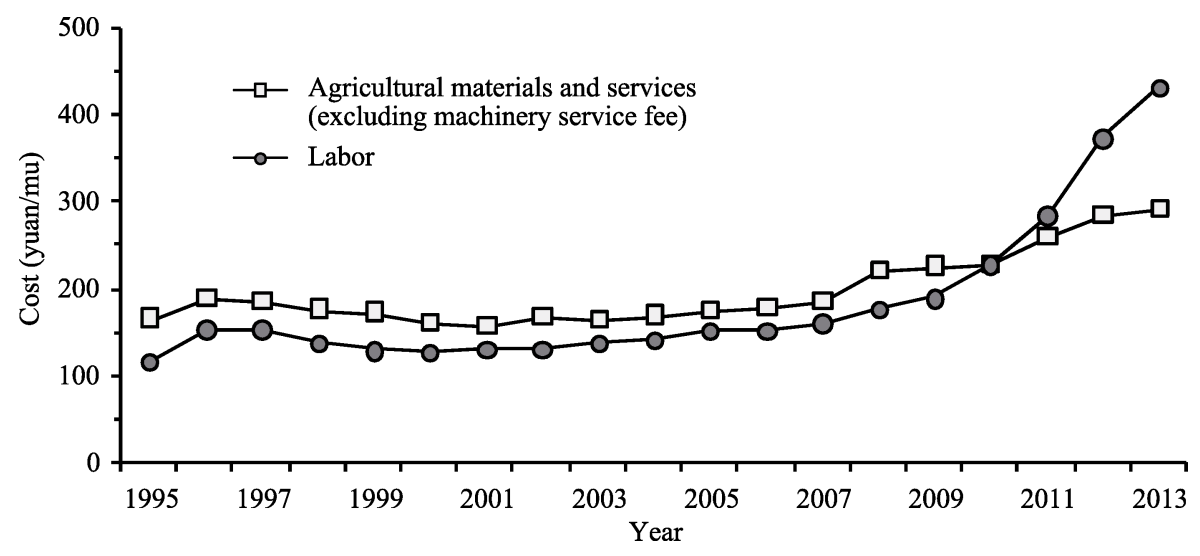

Figure 2 The labor, materials, and service costs for China's three main grain crops since 1995 Data: China Agricultural Production Costs and Returns Compilation

\subsubsection{Farmers' response to the rise of labor costs}

Since 2003, with the rapid rise of the price of the agricultural labor force, the capital investment structure in agricultural production in China has tended to rise in proportion with labor-saving input, especially the input of machinery. From 2003 to 2013, the machinery service fee grew $419 \%$, and pesticides fee also increase $193 \%$, while the fees for seedlings, chemical fertilizer \& farmyard manure, and irrigation \& drainage increased only by $193 \%$, $190 \%, 147 \%$ and $59 \%$, respectively. The previous major input of labor-saving animal power was gradually replaced by machinery, decreasing by $33 \%$ (Figure 3 ). Owing to the fast increase in labor-saving input, the per mu labor use for three main grain crops (rice, wheat and maize) in China decreased 44\% from 11.1 days to 6.2 days. Therefore, although the price of the agricultural labor force increased dramatically during this period, the labor cost proportion of agricultural production in China did not rise sharply, increasing only from $36.5 \%$ to $41.8 \%$. 


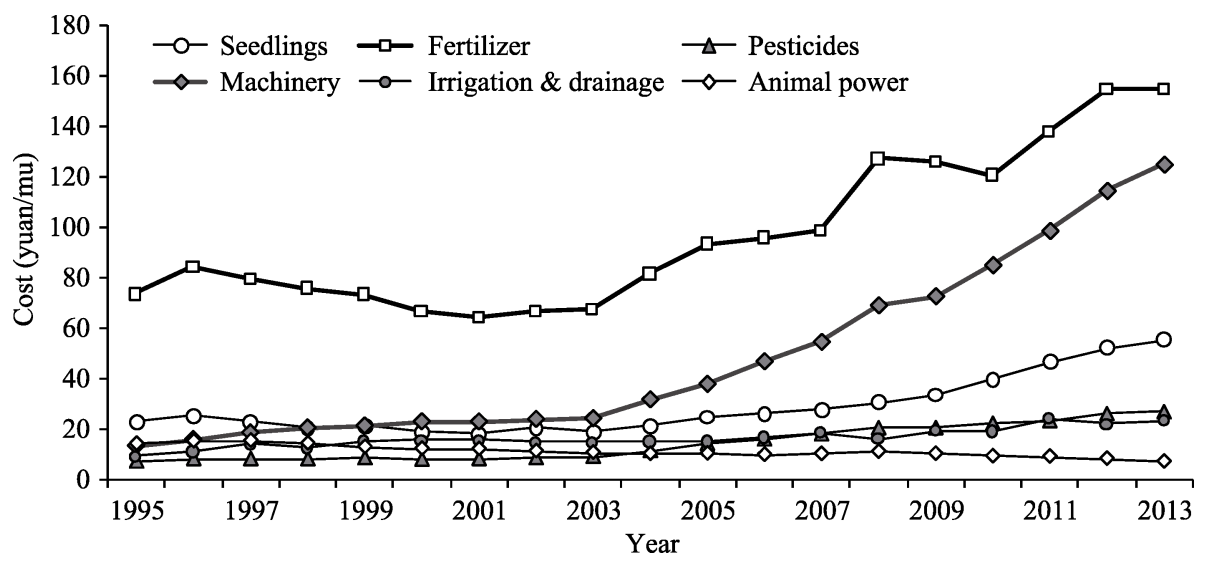

Figure 3 Different types of materials and service costs for China's three main grain crops since 1995 Data: China Agricultural Production Costs and Returns Compilation

\subsection{Different responses of farmers between mountainous and plain areas}

\subsubsection{Slow agricultural mechanization in mountainous areas}

To better reveal the differences in the development of agricultural machinery between plains and mountainous areas, we examine the development of agricultural machinery of Heilongjiang and Chongqing, the typical representatives for plains and mountainous areas, respectively. Since 2003, the gap between Heilongjiang and Chongqing has expanded significantly, both in the total and per laborer power of agricultural machinery. During the period 2003-2013, the total power of agricultural machinery in Heilongjiang increased by 1.7 times, while that in Chongqing increased by only 0.7 times. Heilongjiang's per laborer power of farm machinery increased by 1.8 times and that of Chongqing by only 1.2 times. The gap of per laborer power between the two regions increased from $1.8 \mathrm{~kW}$ to $4.1 \mathrm{~kW}$ (Figure 4). In addition, the agricultural mechanization level in both regions is significantly different. In 2010, the proportion of machine-harvested maize production in Heilongjiang reached as high as $97 \%$, compared with only $16 \%$ in Chongqing.

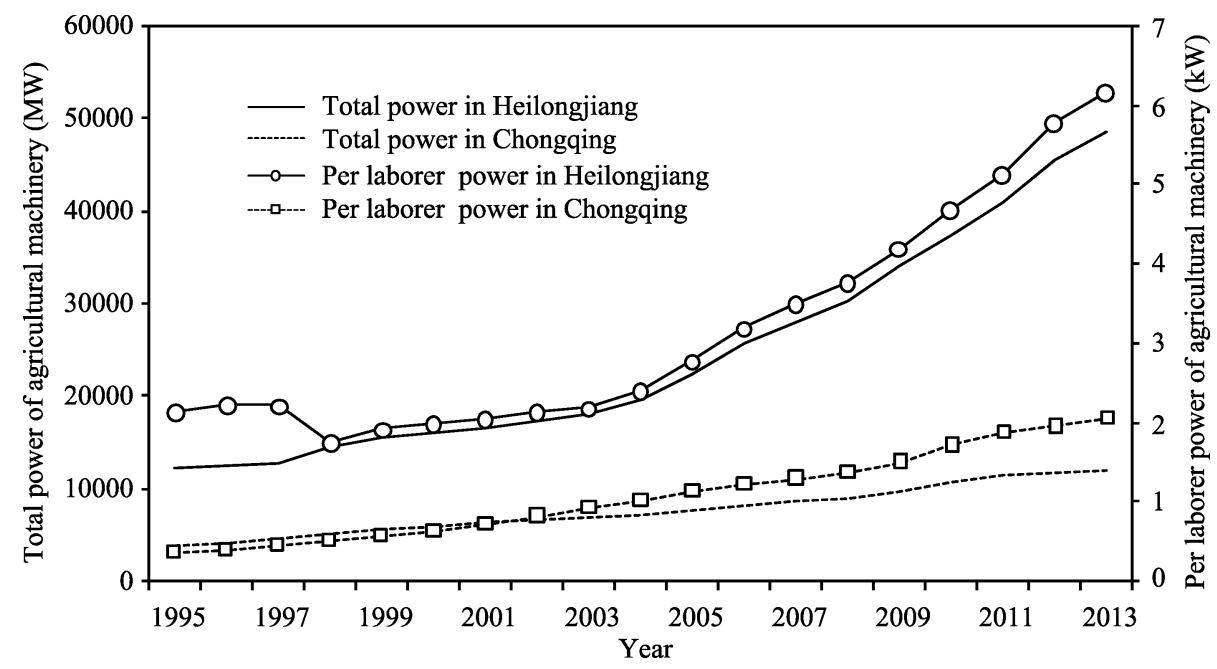

Figure 4 Comparison of agricultural mechanization between Heilongjiang and Chongqing 


\subsubsection{Higher per mu labor use in mountainous areas}

In 2003, the average per mu labor use for maize production in the plain provinces (PPs) was 8.4 days, and decreased $37 \%$ to 5.3 days in 2013, while the average per mu labor use for maize production in mountainous provinces and municipalities (MPMs) declined 30\% from 16.9 days to 11.9 days. Although there was also a significant decrease in per mu labor use in MPMs, the gap between MPMs and PPs was still significant. In 2013, the amount of per mu labor use in MPMs was still more than twice that in PPs. The map of per mu labor use shows that per mu labor use in MPMs, such as southwest China, was significantly higher than that in PPs, such as north China and northeast China, presenting an overall increasing trend from northeast to southwest (Figure 5). Only 3.1 days per mu were needed in Heilongjiang, while the amount of labor use per mu in Guizhou, Yunnan, Gansu, and Chongqing with rugged terrain is still more than 13 days, a difference of more than 3 times compared with Heilongjiang.

\subsubsection{Mounting share of agricultural labor costs in mountainous areas}

Because of the slow development of mechanization in mountainous areas, the growth rate of agricultural machinery input is lower than the rate at which agricultural labor costs rise. Therefore, the cost savings resulting from increased labor-saving input are not enough to offset the increased labor costs. Taking maize cultivation as an example, its labor cost share of MPMs, except for Sichuan, generally showed a significant upward trend during 2003-2013. The average share of the seven MPMs increased from 53.82\% in 2003 up to $63.10 \%$ in 2013. By contrast, the labor cost share of PPs, except for Hebei and Jiangsu, showed a significant downward trend during 2003-2013. The average share of the seven PPs declined from $43.88 \%$ in 2003 to $30.68 \%$ in 2013 (Figure 6).

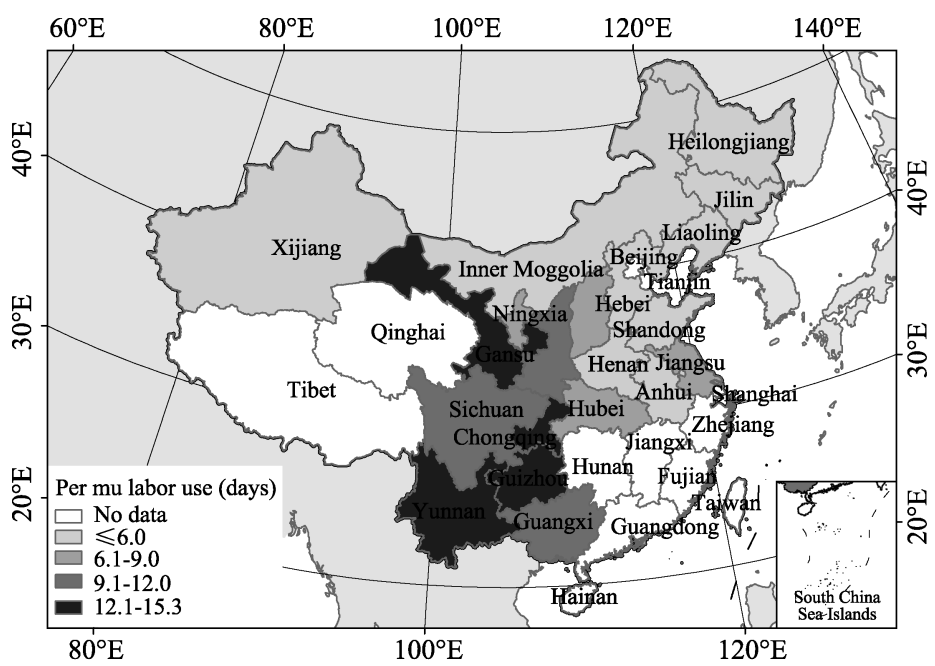

Figure 5 Per mu labor use for maize cultivation at provincial level in 2013

\subsection{Regional differences in agricultural labor productivity and net profit}

\subsubsection{Differences in agricultural labor productivity}

Nationally, the increasing input of agricultural machinery has effectively replaced the labor force, thereby promoting the rapid increase of agricultural labor productivity. Again taking 


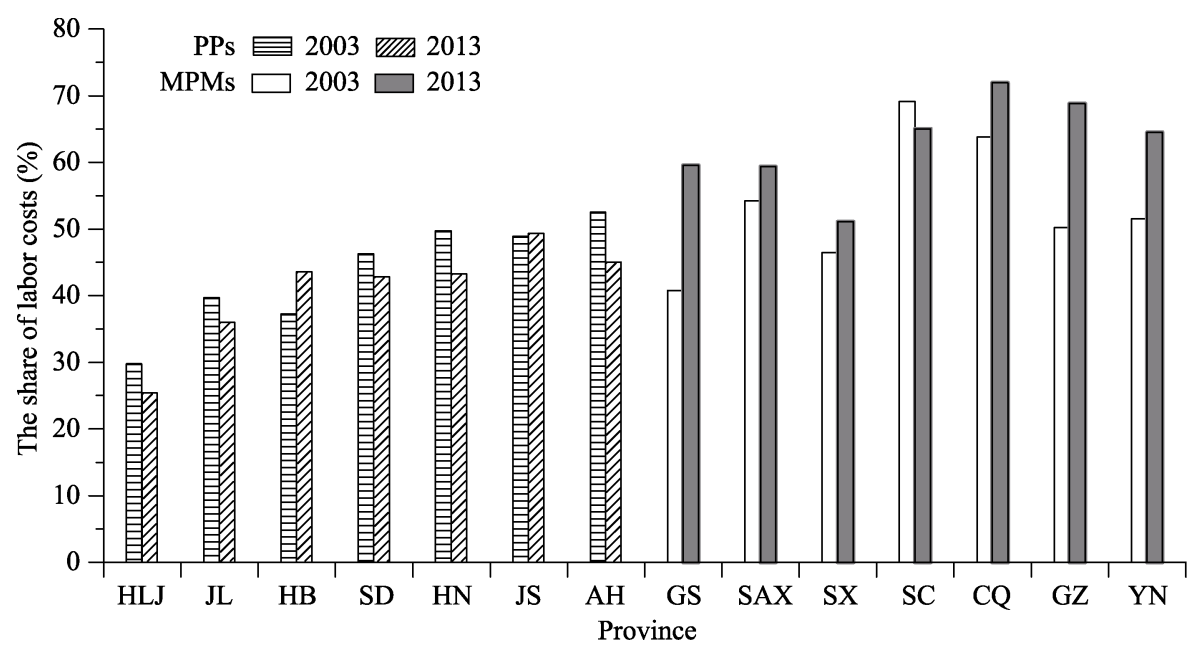

Figure 6 Changes in the proportion of agricultural labor costs (maize) between MPMs and PPs

Notes: $\mathrm{HLG}=$ Heilongjiang, $\mathrm{JL}=$ Jilin, $\mathrm{HB}=$ Hebei, $\mathrm{SD}=$ Shandong, $\mathrm{HN}=$ Henan, JS $=$ Jiangsu, $\mathrm{AH}=$ Anhui, $\mathrm{GS}=$ Gansu, $\mathrm{SAX}=$ Shaanxi, $\mathrm{SX}=$ Shanxi, $\mathrm{SC}=$ Sichuan, $\mathrm{CQ}=$ Chongqing, $\mathrm{GZ}=$ Guizhou, $\mathrm{YN}=$ Yunnan

maize cultivation as an example, from 1990 to 2003, agricultural labor productivity maintained slow growth, while after 2003, with a substantial increase in investment in machinery, it has risen rapidly at an average annual rate of $8.5 \%$ (Figure 7 ).

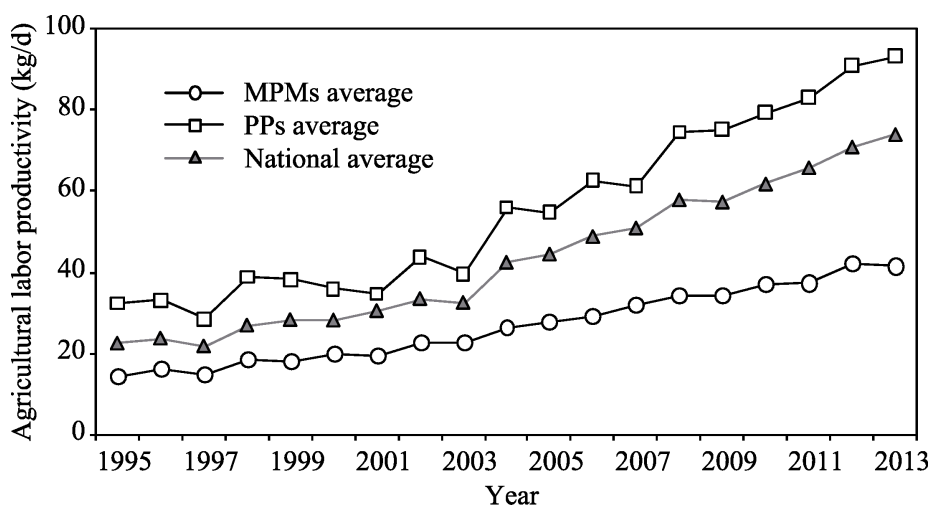

Figure 7 Changes of average labor productivity in maize cultivation between MPMs and PPs

The significant disparity in the agricultural mechanization level under different topographical conditions leads to the difference of per mu labor use and further to a disparity in agricultural labor productivity. Since 2003, the gap of average labor productivity between MPMs and PPs has shown a distinct widening trend. In 2003, the average labor productivity of the seven MPMs was $22.55 \mathrm{~kg} / \mathrm{d}$, while that of the seven PPs was $39.53 \mathrm{~kg} / \mathrm{d}$, the latter being 1.75 times the former. By 2013, the average labor productivity of the seven MPMs increased to $41.38 \mathrm{~kg} / \mathrm{d}$, while that of the seven PPs increased sharply to $93.24 \mathrm{~kg} / \mathrm{d}$, expanding the gap to 2.25 times (Figure 7). The same conclusion is reached by calculating the output value per laborer.

\subsubsection{Differences in agricultural net profit}

Due to the slow increase in agricultural labor productivity in mountainous areas, agricultural labor costs cannot be squeezed effectively by increasing relatively cheap mechanical inputs, 
like in the plains, as rising labor prices have resulted in a decrease in net profit in mountainous areas. Comparing maize production in MPMs and PPs, the net profit of the whole nation has been fluctuating since 2000 owing to the price fluctuation. However, the gap of net profit between the PPs and MPMs has shown an increasing trend. The gap of per mu net profit (comparable price, without land cost) increased from 102 yuan to 197 yuan during 2004 to 2013 (Figure 8).

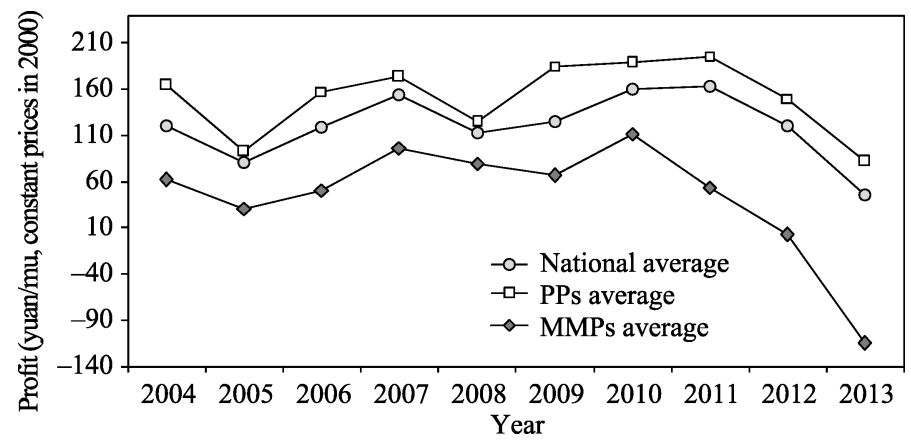

Figure 8 Changes in net profit of maize cultivation between MPMs and PPs

By comparing the per mu net profit of every province and municipality in 2004 and 2013, we find that both MPMs and PPs' per mu net profits show a downward trend, but the decline in the MPMs was greater than that in the PPs. Except for Shanxi, all MPMs' per mu net profit dropped drastically. The average per mu net profit in Chongqing, Guizhou, Yunnan, Shaanxi, and Gansu even dropped below zero, which is in sharp contrast to PPs (Table 1).

Table 1 Comparison of maize net profits in MPMs and PPs (yuan/mu, constant price in 2000)

\begin{tabular}{llrrr}
\hline Type & \multicolumn{1}{c}{ Name } & 2004 & 2013 & Change \\
\hline & Chongqing & 105.86 & -139.00 & -244.86 \\
& Sichuan & 169.91 & 7.14 & -162.77 \\
& Guizhou & 15.86 & -367.73 & -383.59 \\
MPMs & Yunnan & -3.86 & -208.22 & -204.35 \\
& Shaanxi & 42.17 & -47.53 & -89.70 \\
& Gansu & -49.97 & -188.38 & -138.40 \\
& Shanxi & 154.62 & 140.00 & -159.94 \\
\hline \multirow{3}{*}{ PPs } & Jiangsu & 244.06 & 84.12 & -136.85 \\
& Anhui & 201.81 & 64.96 & -17.04 \\
& Jilin & 56.91 & 39.87 & 15.10 \\
& Heilongjiang & 75.19 & 90.29 & -117.72 \\
& Henan & 179.29 & 61.57 & -24.39 \\
& Hebei & 177.45 & 153.06 & -132.42 \\
\hline
\end{tabular}

\subsection{Land-use and land-cover change in mountainous areas}

\subsubsection{Land-use change}

(1) Farmland change

During the period 1990-2000, farmland in Chinese MCs was in a stage of increasing ow- 
ing to massive land reclamation. The farmland area increased by $1.23 \%$ in this decade. The newly cultivated land was mainly distributed in northeast China, while there was also substantial land reclamation in Xinjiang, Ningxia, and Gansu provinces (Figure 9). PCs and HCs increased by $0.71 \%$ and $3.22 \%$, respectively, during this decade. After 2000, the land reclamation in MCs lessened quite obviously, and the cultivated area has decreased. During the period 2000-2010, the cultivated land in MCs decreased by $1.13 \%$, while that in PCs and HCs decreased by $0.20 \%$ and $1.04 \%$, respectively.
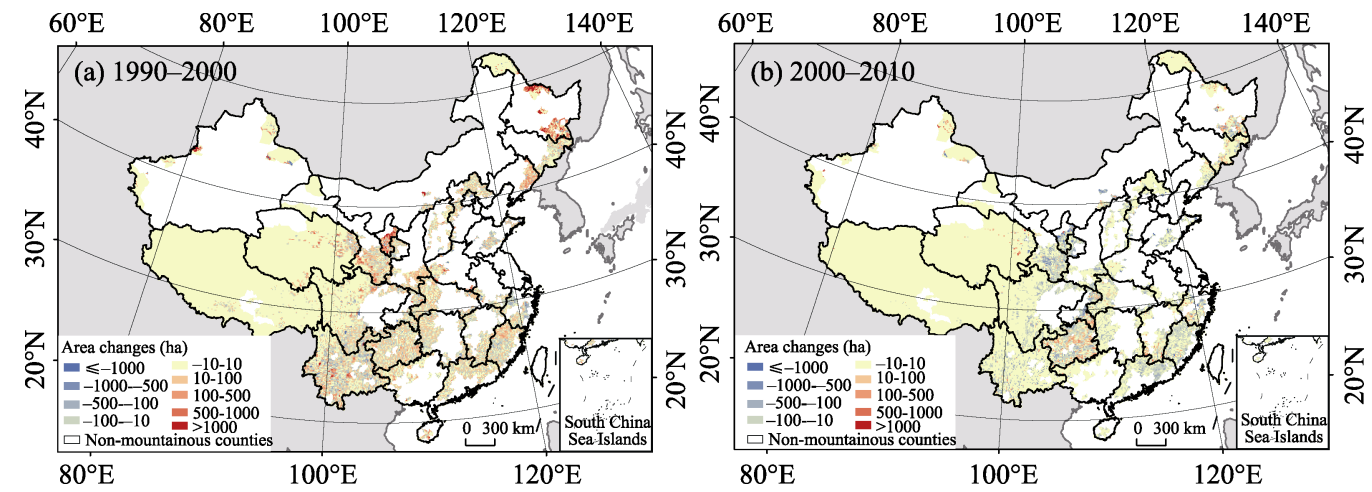

Figure 9 Farmland area changes from 1990 to 2010 in Chinese MCs

Notes: Each pixel in Figures 9 and 10 is $10 \mathrm{~km} \times 10 \mathrm{~km}$.

From 1990 to 2000 , there were 468 MCs with a net decrease of farmland, accounting for $52 \%$ of the total number of MCs, while the proportions of counties with a net decrease of farmland in PCs and HCs were $71 \%$ and $56 \%$, respectively. The high proportion of net decrease in PCs was caused by massive construction land expansion in the coastal plain areas. During 2000-2010, the changes of cultivated land in PCs were similar to those in the previous decade, and the number of counties with a net decrease of farmland increased by 61 , with the proportion increasing to $78 \%$. However, the number in MCs and HCs increased significantly, especially in MCs, where the number increased from 468 to 712 and the proportion expanded to $79 \%$. Correspondingly, the number of MCs with a net increase of farmland decreased from 411 to 114 (Table 2). Overall, since 2000, the reduction of farmland in MCs of China is more evident than in HCs and PCs.

Table 2 Numbers of counties with different types of farmland area changes

\begin{tabular}{|c|c|c|c|c|c|c|}
\hline \multirow{2}{*}{ Type } & \multicolumn{3}{|c|}{ 1990-2000 (Number) } & \multicolumn{3}{|c|}{ 2000-2010 (Number) } \\
\hline & Net increased & Unchanged & Net decreased & Net increased & Unchanged & Net decreased \\
\hline $\mathrm{PCs}$ & 252 & 3 & 615 & 182 & 12 & 676 \\
\hline $\mathrm{HCs}$ & 234 & 1 & 303 & 75 & 8 & 455 \\
\hline MCs & 411 & 25 & 468 & 114 & 78 & 712 \\
\hline
\end{tabular}

A further comparison of Chongqing and Heilongjiang shows that Chongqing, the representative of mountainous areas, decreased its farmland by $1.9 \%$ from 2000 to 2010 , with all 13 MCs showing a decreasing trend; meanwhile Heilongjiang, with relatively good topographical conditions, increased its farmland by $0.07 \%$ during 2000-2010, and 12 out of 15 MCs' farmland area remained about the same or increased only slightly. 


\section{(2) Forest change}

During the period 1990-2000, the decrease of forests in the MCs was mainly distributed in northeast China, chiefly due to farmland expansion and deforestation. Fujian, Zhejiang, and western Xinjiang had obvious forest growth, while deforestation and afforestation activities coexisted in southwest China (Figure 10). During this period, the forest area in Chinese MCs decreased by $0.4 \%$, while that in the PCs and HCs increased by $0.87 \%$ and $1.6 \%$ respectively.
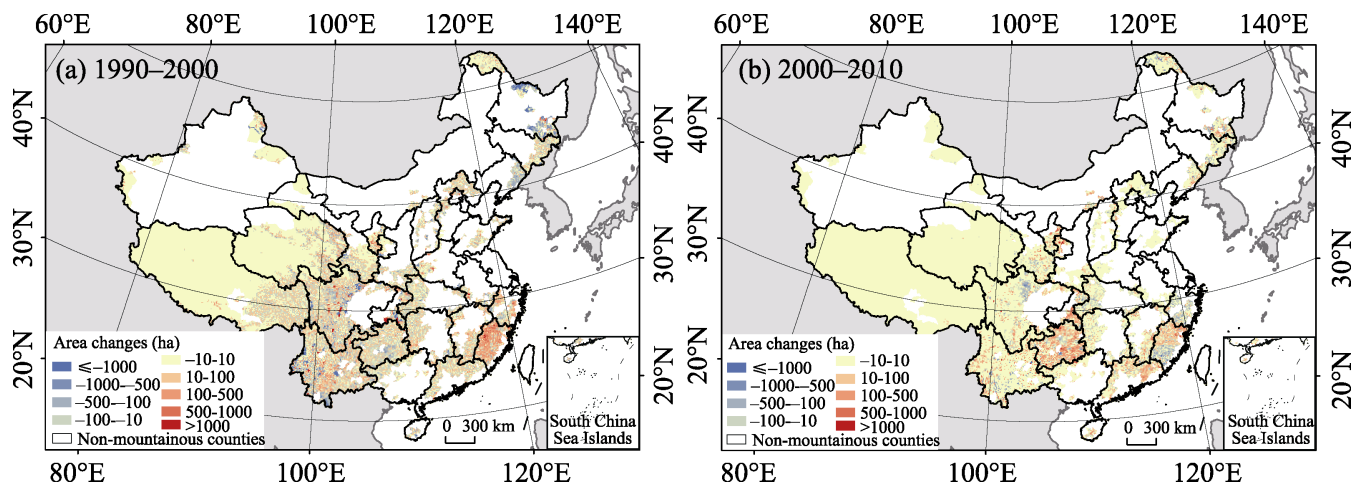

Figure 10 Forest area changes from 1990 to 2000 in Chinese MCs

During the period 2000-2010, the range of forest reduction in Chinese MCs obviously shrank, but there was no region of massive forest reduction. The implementation of the Grain for Green Project (GGP) and other ecological projects combined with the natural restoration of abandoned farmland have led to the continuous increase of forest area in Chinese MCs, especially in ecologically fragile areas, such as Guizhou, Chongqing, and Loess Plateau. During this period, the forest area in MCs increased by $0.19 \%$, while that in PCs and HCs decreased by $0.52 \%$ and $0.42 \%$, respectively. Similarly, comparing the forest area change in Chongqing and Heilongjiang, the forest area in Chongqing increased by $1.70 \%$ during 2000-2010, while that in Heilongjiang decreased by $0.24 \%$.

\subsubsection{NDVI change}

(1) NDVI changes in mountainous areas from 2000 to 2013

During 2000-2013, the annual average NDVI value in Chinese MCs tended to increase gradually at an increase rate of $9.9 \%$. Among all the provinces (MCs range only), Inner Mongolia and Ningxia had the largest increase rates of $33 \%$ and $23 \%$, respectively, followed by Shanxi, Gansu, Qinghai, Guizhou, Guangxi, Hainan, Guangdong, and Fujian provinces, which had increase rates of more than $10 \%$. The increase of NDVI in northeast China was the smallest, while the increase rates in Heilongjiang, Jilin, and Liaoning provinces were less than $4 \%$ during the period; the local reduction of NDVI in these areas might have been caused by the decrease of precipitation (Figure 11).

(2) Correlation between NDVI and land-use change

The Pearson's correlation coefficient between the rate of farmland area change (2000-2010) and the rate of NDVI change (2000-2013, within farmland area in 2000) in the MCs at provincial level reached $-0.70(P<0.01)$, showing a strong negative correlation. On the other hand, the Pearson correlation coefficient of forest area change rate (2000-2010) and NDVI change rate (2000-2013) ranged up to $0.91(P<0.01)$, showing a strong positive 
correlation (Figure 12).

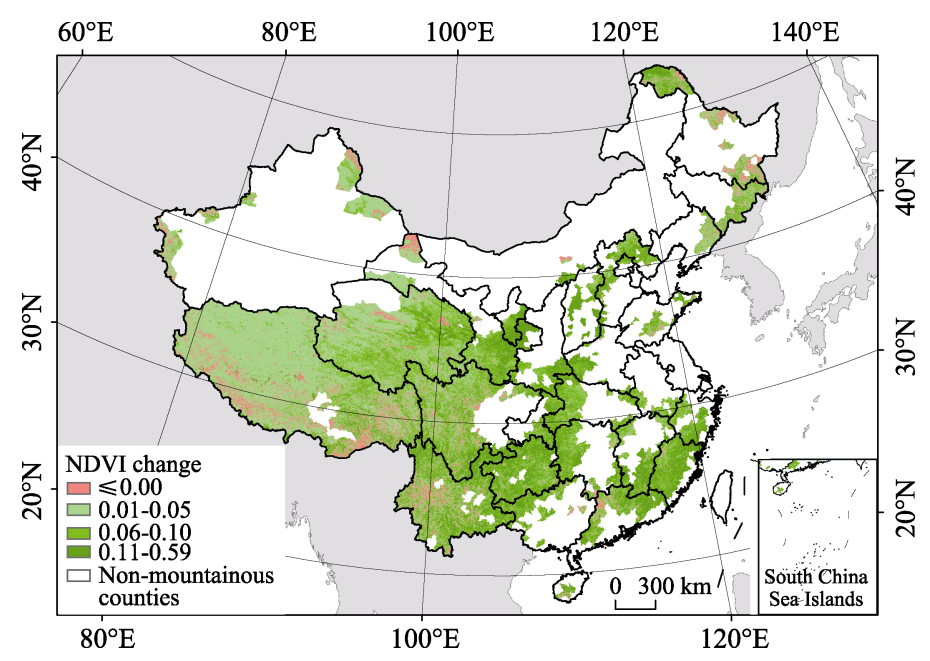

Figure 11 NDVI variations within Chinese MCs from 2000 to 2013
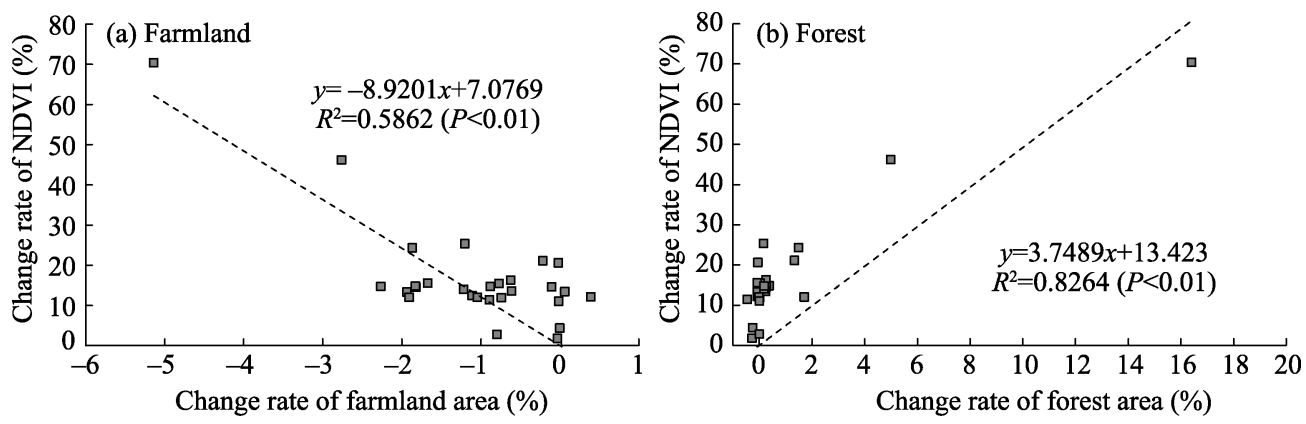

Figure 12 Correlation between farmland and forest area change rate and the NDVI change rate within MCs

\section{Discussion}

\subsection{Evidence of and reasons for farmland marginalization in mountainous areas}

In this study, we analyzed the changes in agricultural cost structure and compared the different response capabilities of farmers between mountainous and plain areas since 2003. We established that the root cause of farmland marginalization and abandonment always occurring in mountainous areas rather than plain areas is the sharp decline in net profit, even to below zero (zero rent), which is in accordance with the results of Zhang et al. (2014b). The sharp drop in net profit is the result of larger per mu labor use and low agricultural labor productivity. The declining rent demonstrates that farmland in Chinese mountainous areas is in the process of marginalization. Furthermore, since 2000, farmland and forest area in Chinese MCs have opposite growth trends, which is consistent with rising agricultural labor costs and decreasing net profits. The results of the correlation analysis confirm the trend of farmland decrease and forest expansion in Chinese mountainous areas since 2000, which provides good realistic evidence for this study's findings. In addition, a national scale sample survey for farmland abandonment in Chinese mountainous regions, which was carried out by our research team, established that $78.3 \%$ of surveyed villages have experienced 
farmland abandonment and about 15\% of farmland was abandoned in 2015 (Li et al., 2017b). Massive farmland abandonment occurred mainly after 2000, which is in line with the trend toward a rapid rise of agricultural labor costs.

\subsection{The mechanism of farmland marginalization}

The main force driving farmland marginalization that this study revealed is similar to that in western Europe (Doorn et al., 2007; Gellrich et al., 2007) and Latin America (Aide et al., 2004), that is, farmland marginalization in Chinese mountainous areas is the result of rural exodus caused by rapid industrialization and urbanization. By summarizing the evidence of farmland marginalization in Chinese mountainous areas in this and other existing research (Rudel et al., 2005; Tian et al., 2009; Zhang et al., 2014a, b; Yan et al., 2016; Li et al., 2017a), we can establish the mechanism of farmland marginalization as follows. As urbanization and industrialization provide abundant job opportunities, the wage for the off-farm labor force rises rapidly after the Lewis turning point. Rising farming opportunity cost leads more and more farmers, especially young farmers, to choose to seek off-farm work in urban areas rather than be engaged in agricultural production. This outcome further raises the price of agricultural labor. Against this backdrop, improving agricultural labor productivity and reducing labor input is the most efficient way to avoid farmland marginalization. The ways to improve agricultural labor productivity include maximizing labor productivity by adopting large-scale and intensive farming practices, using labor-saving machinery to substitute expensive agricultural labor (Zhu et al., 2007), or increasing the cultivated area of crops with higher labor productivity to reduce the costs induced by the rising wage of agricultural labor (Tian et al., 2009). The vast differences in natural conditions between mountainous and plain areas, especially topographical conditions, lead to different choices of farmers in ways to improve agricultural labor productivity. In plain areas, farmers can substantially increase the input of labor-saving agricultural machinery to replace labor, thereby significantly increasing labor productivity, reducing labor costs, and avoiding farmland marginalization. In mountainous areas, rugged terrain seriously impedes the development of agricultural mechanization. Farmers in these areas normally improve their labor productivity only by adjusting the farming structure and system. However, the effect of such adjustment is limited and thus, their agricultural labor productivity grows slowly. Then, the share of labor costs of agricultural production increases, entailing declining profitability in agricultural production and the inevitable farmland marginalization (Strijker et al., 2005).

From the viewpoint of agricultural labor force out-migration, in the process of land marginalization, owing to the rugged terrain in mountainous areas, the per mu labor use is obviously higher than that in plain areas. Hence, the per laborer farming area in mountainous areas is far less than that in plain areas. During the process of rapid urbanization, a rural exodus would lead to an increase of machinery inputs in the plains to substitute for reducing agricultural laborers, thereby resulting in a large increase in per laborer farming area. However, the out-migrated agricultural labor in mountainous areas cannot be substituted by agricultural machinery. Consequently, poor and remote farmland would be marginalized when all agricultural land cannot be managed, and then this farmland would be abandoned (Figure 13). 


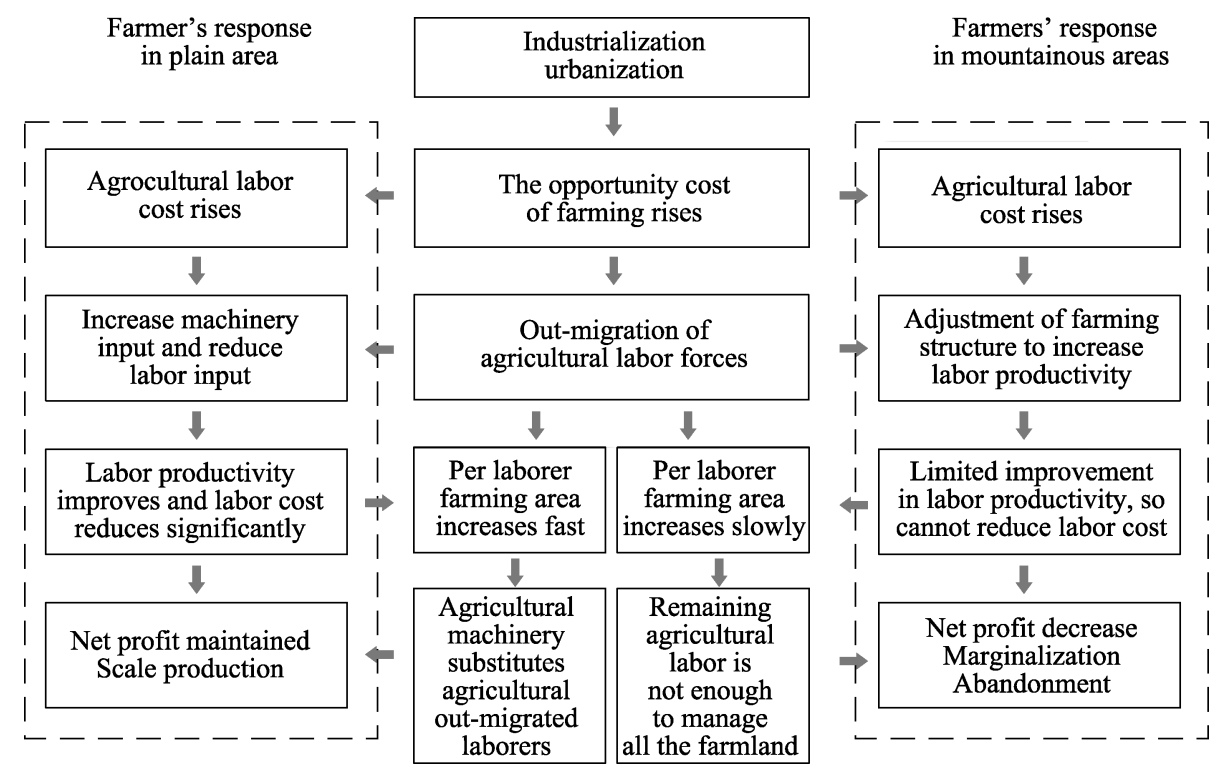

Figure 13 Mechanism of farmland marginalization in Chinese mountainous areas

\subsection{Policy implications}

Farmland marginalization in mountainous and hilly areas has become a widespread phenomenon when the economy of a country or region develops to a certain level. Farmland marginalization has far-reaching impacts on the socio-economy and ecological environment (Queiroz et al., 2014; Li et al., 2017a). Therefore, eliminating the negative impact of farmland marginalization in mountainous areas should be the focus of future research. With the introduction of the National New-Type Urbanization Plan, China's urbanization process is expected to maintain rapid development. The labor wage will probably continue to rise fast, thereby promoting the out-migration of rural labor in the mountainous areas and the marginalization of cultivated land. Without the implementation of effective public policies, more and more sloping farmland in mountainous areas is likely to be abandoned or shifted to other high-yielding or labor-saving agricultural products, such as fruit, tobacco, and wood.

Generally, the outmigration of rural labor could improve the vegetation cover in ecologically fragile areas (Li et al., 2016). In terms of Chinese mountainous areas, farmland marginalization, combined with firewood substitution and the fading livestock system is highly conducive to improving the ecological environment there (He et al., 2016), and is a powerful guarantee for the success of GGP. However, as a country with very little cultivated land per capita and a large proportion of slopping farmland, the impact of farmland marginalization in mountainous areas on food security could be noteworthy, and thus, is likely to remain an issue that cannot be ignored. According to the analysis results of this study, the key to alleviate farmland marginalization in mountainous areas is to improve agricultural labor productivity. There are two main ways to improve labor productivity. The first is to achieve proper land scale management through land consolidation and farmland transfer to increase the utilization of agricultural machinery, in order to reduce labor input in agricultural production. The second way is to increase the value added of agricultural products, for example, by promoting the cultivation of agricultural products with special local characteristics and 
that cannot be farmed by machinery, in order to raise economic output per laborer.

\section{Conclusions}

With the progress of industrialization and urbanization in China, the out-migration of rural labor forces, and the rising farming opportunity cost have led to noteworthy farmland marginalization in mountainous areas. The economic characteristics of farmland marginalization are as follows.

First, since 2003, driven by the rapid rise of the agricultural labor wage, the input of agricultural machinery has increased sharply. Due to restrictions from topographical conditions, the development of agricultural mechanization in mountainous areas has been hindered. The labor use per mu of agricultural production is far greater than that in the plain areas, resulting in an obvious increase in farming cost.

Second, due to differences in the level of mechanization, the gap of average labor productivity in maize production between mountainous and plains areas widened from 1.75 times in 2003 to 2.25 times in 2013 .

Third, because of the slow growth of agricultural labor productivity in mountainous areas, with the labor wage increase, net profit of agricultural production declined sharply. In 2013, the net profit of maize production in the MPMs generally dropped to below zero.

Fourth, owing to farmland marginalization in mountainous areas, the restoration of abandoned farmland and the implementation of GGP have led to a general trend of decreasing cultivated areas, increasing forest areas, and increasing NDVI in mountainous areas since 2000.

Finally, the main driving force of the marginalization of cultivated land in China's mountainous areas is the rising cost of agricultural opportunity and the out-migration of rural labor forces, caused by industrialization and urbanization. The key reason is that mountainous terrain restricts the substitution of machinery and labor productivity increases slowly. The root cause of farmland marginalization and abandonment is the decline of net profit to below zero, which results from the sharp increase in the agricultural labor cost. At the household level, farmland marginalization is the result of optimal allocation of household land and labor resources. At the regional level, farmland marginalization is led by the combined effect of a slow increase in agricultural productivity and a drastic reduction in the agricultural labor force.

\section{References}

Aide T M, Grau H R, 2004. Globalization, migration, and Latin American ecosystems. Science, 305(5692): 1915-1916.

Alcantara C, Kuemmerle T, Prishchepov A V et al., 2012. Mapping abandoned agriculture with multi-temporal MODIS satellite data. Remote Sensing of Environment, 124: 334-347.

Chen Y, Li X, Tian Y et al., 2009. Structural change of agricultural land use intensity and its regional disparity in China. Journal of Geographical Sciences, 19(5): 545-556.

Chuang Y, 2014. Investigation and thinking on the cropland abandonment in Jingning County. Agricultural Development and Equipment, (8): 21-22. (in Chinese)

Doorn A M V, Bakker M M, 2007. The destination of arable land in a marginal agricultural landscape in South Portugal: An exploration of land use change determinants. Landscape Ecology, 22(7): 1073-1087.

Fang C, Du Y, Wang M, 2009. Migration and labor mobility in China. New York: United Nations Development 
Programme, Human Development Report Office.

Gan N, Yin Z, Tan Z, 2015. China Household Finance Survey Report 2014. Chengdu: Southwestern University of Finance and Economics Press. (in Chinese)

Gellrich M, Baur P, Koch B et al., 2007. Agricultural land abandonment and natural forest re-growth in the Swiss mountains: A spatially explicit economic analysis. Agriculture, Ecosystems \& Environment, 118(1-4): 93-108.

He W, Yan J, Zhou H et al., 2016. The micro-mechanism of forest transition: A case study in the mountainous areas of Chongqing. Journal of Natural Resources, 31(1): 102-113. (in Chinese)

Huang J, Li L, 2009. Dilemma of idling arable land in mountainous areas and its causes and countermeasures: Take Huitong County as an example. Journal of UESTC (Social Sciences Edition), 11(4): 11-14. (in Chinese)

Jiang X, Zeng H, 2009. Quantifying mountain regions of China: A case study in Sichuan. Mountain Research, 27(1): 24-32. (in Chinese)

Kozak J, 2003. Forest cover change in the Western Carpathians in the past 180 Years: A case study in the Orawa Region in Poland. Mountain Research and Development, 23(4): 369-375.

Lambin E F, Meyfroid P, 2010. Land use transitions: Socio-ecological feedback versus socio-economic change. Land Use Policy, 27(2): 108-118.

Li J, 2013. Study on abandonment of cultivated land in mountain areas based on labor emigration [D]. Chongqing: Southwest University. (in Chinese)

Li S, Li X, 2017a. Global understanding of farmland abandonment: A review and prospects. Journal of Geographical Sciences, 27(9): 1123-1150.

Li S, Li X, Xin L et al., 2017b. Extent and distribution of cropland abandonment in Chinese mountainous areas. Resources Science, 39(10): 1801-1811. (in Chinese)

Li S, Sun Z, Tan M et al., 2016. Effects of rural-urban migration on vegetation greenness in fragile areas: A case study of Inner Mongolia in China. Journal of Geographical Sciences, 70(3): 1622-1631.

Li X, Zhao Y, 2011. Forest transition, agricultural land marginalization and ecological restoration. China Population, Resources and Environment, 21(10): 91-95. (in Chinese)

Li Z, Yan J, Hua X et al. , 2014. Factors influencing the cultivated land abandonment of households of different types: A case study of 12 typical villages in Chongqing Municipality. Geographical Research, 33(4): 721-734. (in Chinese)

Liu C, Li X, 2005. The character and diagnostic criterion for marginiastion of the arable land. Progress in Geography, 24(2): 106-113. (in Chinese)

Lu F, 2012. Wage trends among Chinese migrant workers: 1979-2010. Social Sciences in China, (7): 47-67. (in Chinese)

Luo P, Tang Y, Kang H et al., 2015. Empirical study on factors influencing farmers' willingness to cropland abandonment in Hunan Province. Acta Agriculturae Zhejiangensis, 27(8): 1494-1498. (in Chinese)

Luo S, 2008. Causes and countermeasures of farmland abandonment in Yongding County. Fujian Agricultural Science and Technology, (3): 88-89. (in Chinese)

MacDonald D, Crabtree J R, Wiesinger G et al., 2000. Agricultural abandonment in mountain areas of Europe: Environmental consequences and policy response. Journal of Environmental Management, 59(1): 47-69.

Meyfroidt P, Lambin E F, 2011. Global forest transition prospects for an end to deforestation. The Annual Review of Environment and Resources, 36: 343-371.

Queiroz C, Beilin R, Folke C et al., 2014. Farmland abandonment: Threat or opportunity for biodiversity conservation? A global review. Frontiers in Ecology and the Environment, 12(5): 288-296.

Rudel T K, Coomes O T, Emilio Moranc F et al., 2005. Forest transitions: Towards a global understanding of land use change. Global Environmental Change, 15(1): 23-31.

Shi T, Li X, Xin L, 2016. Analysis of farmland abandonment at parcel level: A case study in the mountainous areas of China. Sustainability, 8(988): 1-19.

Shi T, Xu X, 2016. Extraction and validation of abandoned farmland parcel in typical counties of Chongqing. Transactions of the Chinese Society of Agricultural Engineering, 32(24): 261-267. (in Chinese)

Strijker D, 2005. Marginal lands in Europe: Causes of decline. Basic and Applied Ecology, 6(2): 99-106. 
Tian Y, Li X, Ma G et al., 2010. Influences of labor emigration from agriculture on the production abandonment of cultivated land in ecological sensitive areas. China Land Science, 24(7): 4-9. (in Chinese)

Tian Y, Li X, Xin L et al., 2009. Impacts of the rise of labor opportunity cost on agricultural land use changes: A case study of Ningxia Hui Autonomous Region. Journal of Natural Resources, 24(3): 369-377. (in Chinese)

Wang X, Li X, Tan M et al., 2015. Remote sensing monitoring of changes in winter wheat area in North China Plain from 2001 to 2011. Transactions of the Chinese Society of Agricultural Engineering, 31(8): 190-199. (in Chinese)

Xin L, Li X, Tan M et al., 2011. The rise of ordinary labor wage and its effect on agricultural land use in present China. Geographical Research, 30(8): 1391-1400. (in Chinese)

$\mathrm{Xu} \mathrm{H}$, Zhu H, 2015. Spatial change of China's grain production based on geographical division of natural factors during 1990-2010. Acta Geographica Sinica, 70(4): 582-590. (in Chinese)

$\mathrm{Xu} \mathrm{L}, 2010$. How to solve the problem of farmland abandonment in the process of urbanization: A case study in Sichuan Province. Rural Economics, (3): 21-24. (in Chinese)

$\mathrm{Xu}$ X, Liu J, Zhang Z et al., 2015. Time Series of Land Ecosystem Classification Dataset of China in Five-Year Increments (1990-2010). Global Change Research Data Publishing \& Repository. http://geodoi.ac.cn/WebEn/ doi.aspx?Id=177.

Xu X, Liu J, Zhang Z et al., 2017. A time series land ecosystem classification dataset of China in five-year increments (1990-2010). Journal of Global Change Data \& Discovery, 1(1): 52-59. (in Chinese)

Yan J, Yang Z, Li Z et al., 2016. Drivers of cropland abandonment in mountainous areas: A household decision model on farming scale in Southwest China. Land Use Policy, 57: 459-469.

Yan, J, Zhang Y, Hua X et al., 2016. An explanation of labor migration and grain output growth: Findings of a case study in eastern Tibetan Plateau. Journal of Geographical Sciences, 26(4): 484-500.

Yi M, 2014. Reasons and countermeasures of cultivated land abandonment in Songxi County. Modern Agricultural Science and Technology, (18): 330-331. (in Chinese)

Zhang B, Yang Q, Yan Y et al., 2011. Characteristics and reasons of different households' farming abandonment behavior in the process of rapid urbanization based on a survey from 540 households in 10 counties of Chongqing municipality. Resources Science, 33(11): 2047-2054. (in Chinese)

Zhang X, Yang J, Wang S, 2011a. China has reached the Lewis turning point. China Economic Review, 22(4): 542-554. (in Chinese)

Zhang Y, Li X, Song W, 2014a. Determinants of cropland abandonment at the parcel, household and village levels in mountain areas of China: A multi-level analysis. Land Use Policy, 41: 186-192.

Zhang Y, Li X, Song W et al., 2014b. Land abandonment under rural restructuring in China explained from a cost-benefit perspective. Journal of Rural Studies, 47(47): 524-532.

Zhao J, 2012. Analysis of farmlands abandonment in the context of peasants working out. Journal of Anhui Agricultura Sciences, 40(29): 14518-14520. (in Chinese)

Zhao Y, Zhang M, Li X et al., 2016. farmland marginalization and policy implications in mountainous areas: A case study of Renhuai City, Guizhou. Journal of Resources \& Ecology, 7(1): 61-67.

Zhu H, Li X, Xin L, 2007. Intensity change in cultivated land use in China and its policy implications. Journal of Natural Resources, 22(6): 907-915. (in Chinese) 